\title{
QUANTIFYING THE UNCERTAINTY OF SOLAR PHOTOVOLTAIC SOFT COSTS IN THE “COST OF RENEWABLE ENERGY SPREADSHEET TOOL” (CREST) MODEL
}

\author{
S. M. Syal ${ }^{\otimes}$ and E. F. MacDonald \\ Stanford University, United States of America \\ $\triangle$ syalsm@stanford.edu
}

\begin{abstract}
While solar photovoltaics are projected to grow, major financial barriers exist that impede installation. Soft costs (human-driven costs) can account for over half of total project costs and are often simplified in typical models. We use the National Renewable Energy Laboratory's "Cost of Renewable Energy Spreadsheet Tool" to quantify uncertainty of three soft cost inputs and their influence on the output cost of energy using variance-based sensitivity indices. We then suggest how the development process and model can be redesigned to represent the complexities of this socio-technical system.
\end{abstract}

Keywords: uncertainty, engineering design, sustainability

\section{Introduction}

Renewable energy technologies (RET) are the fastest growing source of energy at $7.1 \%$ per annum and statistics show that RET will increase from $4 \%$ to $15 \%$ of the global energy demand in the next 20 years (BP, 2019). Solar energy is projected to grow 10 times in the next 20 years to help meet that demand (BP, 2019); however, current industry surveys show that many barriers exist for solar projects, particularly for larger-scale photovoltaic (PV) projects. A study conducted by the National Renewable Energy Laboratory (NREL) under the United States Department of Energy (US DoE) found that the largest reported barriers to solar projects were "financial in nature" (Hubbell et al., 2009). Costs are a significant driver for decision-making in solar implementation and can influence the design of the overall system, yet methods for estimating and predicting costs in the solar industry are typically unsophisticated compared to other highly technical industries.

A solar developer must consider three major areas of costs during project development: (1) hard costs, defined as the cost of hardware, such as panels and inverters; (2) financial costs, defined as financerelated and tax-related terms; and (3) soft costs, defined as human-driven costs including permitting, land-leasing, and installation labour costs. Soft costs in particular can account for a major portion of total project costs; an analysis conducted by NREL determined that soft costs can account for up to $63 \%$ of total project costs (Fu et al., 2018). The US DoE has prioritized the reduction of human-drive costs for solar projects in recent years and are leading efforts in many diverse areas to facilitate cost reduction (Department of Energy, 2019); however, soft costs continue to persist as a significant barrier for solar PV projects and the uncertainty of the costs can greatly shift how engineering systems are designed. Permitting processes that vary between jurisdictions can determine how the PV systems themselves are designed, such as how many panels are used and where the systems are installed. 
Installation cost fluctuations can influence the type of work force that is hired and what kinds of technical issues a system might experience during its lifetime. Land lease costs can also wildly vary based on negotiations with landowners and can dictate how much land is available for the project. While these are just a few examples of how uncertainty of soft costs influences the engineering design of solar plants, further examination of publicly available cost models shows that a typical cost model does not account for uncertainty in its soft cost inputs. In stark contrast to the highly technical modelling of the design of physical systems, human driven costs in solar modelling are linearly additive and do not reflect the true variability that is present in the industry. Quantifying the uncertainty of soft costs could present a new approach to designing models of sociotechnical systems, unlock new insights into how soft costs influence solar project design, and suggest focused research areas to accelerate soft cost reduction.

This paper presents an analysis of a solar cost model built by NREL called the "Cost of Renewable Energy Spreadsheet Tool" (CREST) model (National Renewable Energy Laboratory, 2011) and quantifies the uncertainty of three soft cost inputs using Sobol' indices, a variance-based sensitivity index. Variance-based sensitivity indices measure the influence each input has on the output variance and accounts for interactions between inputs; these indices can be used to determine the relative importance of the inputs and better understand how the model design contributes to the output. The CREST model accepts a wide range of inputs to calculate the output levelized cost of energy (LCOE). LCOE is a cost per energy value and is used in energy finance to compare the financial viability of different energy sources and make project decisions; the smaller the LCOE, the more financially viable the project. To understand how the LCOE varies based on the soft cost inputs, we first explore the structure of the CREST model and choose three soft costs for the analysis. We define input distributions for each of these inputs based on literature and industry data. We then propagate uncertainty through the model for a commercial-scaled PV solar plant and calculate Sobol' indices. We use the results to determine relative importance of the soft cost inputs and how they influence the output LCOE. Overall, we use this analysis to better understand current solar industry development challenges and show how uncertainty quantification can help illuminate areas of opportunity for systems design. We conclude by suggesting improvements for both cost model design and solar development process design.

\section{Background}

The following section provides a review of soft costs in solar PV projects, existing publicly available solar cost models, and a background of variance-based sensitivity indices.

\subsection{Solar PV soft costs}

The US DoE Solar Energy Technologies Office defines soft costs to be "non-hardware costs," including (but not limited) to customer acquisition, permitting, interconnection, and installation costs (Department of Energy, 2019). The challenges associated with these costs have not only hindered solar installations in the past, but also pose significant challenges for future installations. For example, jurisdictions across the U.S. require different permitting and inspection processes, resulting in lengthened timelines and wildly varying prices for developers, depending on where the project is. Municipalities, particularly in rural areas, often don't have solar project requirements written into the code that governs new projects, forcing developers to work with the local government to update the code. Additionally, utilities may require significant interconnection fees and upgrades to existing infrastructure to connect projects to the grid.

As part of the SunShot program, a nationwide initiative to make solar energy technologies costcompetitive, the US DoE has offered a diverse set of activities, programs and funding opportunities in an effort to reduce soft costs. These activities and programs fall in the following categories: Business Innovation, Training, Networking and Technical Assistance, and Data Analysis (Department of Energy, 2019). Additionally, the US DoE has funded two rounds of the Solar Energy Evolution and Diffusion Studies to support data-driven research to understand customer motivations and barriers to solar adoption (US Department of Energy, 2016a). For more information on current US DoE soft cost programs, see (US Department of Energy, 2016b). While these efforts and others at the state and local levels exist, the soft costs are still estimated to be a significant portion of the total project costs, approximately 35\%-63\%, depending on the size of the project (Fu et al., 2018). 


\subsection{Solar PV cost models}

Cost modelling is a crucial part of solar development; regardless of the size of the project, the decision to install a project is closely tied to its financial viability. While most models of solar project designs and costs are proprietary to the developer, Table 1 provides a review of the main solar cost models that are available to the public.

Table 1. Publicly available solar project design and cost models

\begin{tabular}{|c|c|c|}
\hline Model & Owner & Description \\
\hline $\begin{array}{c}\text { Cost of Renewable Energy } \\
\text { Spreadsheet Tool (CREST) }\end{array}$ & $\begin{array}{c}\text { National Renewable } \\
\text { Energy Laboratory }\end{array}$ & $\begin{array}{c}\text { The CREST model is a Microsoft Excel based cost } \\
\text { model that incorporates hard costs, soft costs, financing } \\
\text { terms, and outputs levelized cost of energy and a cash } \\
\text { flow analysis. (National Renewable Energy Laboratory, } \\
\text { 2011) }\end{array}$ \\
\hline $\begin{array}{c}\text { System Advisor Model } \\
\text { (SAM) }\end{array}$ & $\begin{array}{c}\text { National Renewable } \\
\text { Energy Laboratory }\end{array}$ & $\begin{array}{c}\text { SAM incorporates technical models with financial } \\
\text { models for a more holistic and detailed sociotechnical } \\
\text { analysis of solar projects. SAM can be interfaced via a } \\
\text { graphical user interface or via a python wrapper. (Blair et } \\
\text { al., 2017) }\end{array}$ \\
\hline PVsyst & $\begin{array}{c}\text { PVsyst: Photovoltaic } \\
\text { Software }\end{array}$ & $\begin{array}{c}\text { PVSyst is a free software that combines project data, } \\
\text { meteorological data, and economic data to analyse solar } \\
\text { PV project viability and design. (PVSyst, 2019) }\end{array}$ \\
\hline PV*SOL & Valentin Software & $\begin{array}{c}\text { PV *SOL is a licensed-based software that offers detailed } \\
\text { tools for 3D shade analysis, solar output, and economic } \\
\text { forecasting for solar PV projects. (Valentin Software, } \\
\text { 2019) }\end{array}$ \\
\hline
\end{tabular}

Other models for solar PV projects exist solely for hardware-based analyses and do not include a full range of sociotechnical factors, thus were not included in Table 1. The cost models listed in Table 1 have varying levels of capability for soft cost analysis and are purely deterministic. We chose to use the CREST model for our analysis due to the ease of use for our uncertainty quantification analysis.

\subsection{Variance-based sensitivity analysis}

Variance-based sensitivity analysis is used to investigate how inputs in a numerical model influence the variance of the output; the resulting analysis is a form of global sensitivity analysis (SA), which considers the full space of inputs and their interactions, rather than local SA, which focuses on sensitivity around a particular value (Pianosi et al., 2016). Variance-based SA can be used to evaluate which inputs have a significant effect on the output and in the case of complex models, de-parametrize the model (disregard unimportant inputs in the model analysis).

Sobol' indices are based on variance decompositions (Sobol', 1993) and can be calculated assuming the input variables are independent. Total-order Sobol' indices measure the overall contribution of each input to the output variance, including interaction effects. If the total index is small, we can consider the input unimportant in the analysis. Equation (1) shows the basic form for the total-order index, $S_{T i}$, using notation from (Saltelli et al., 2004).

$$
S_{T i}=\frac{E\left(V\left(Y \mid X_{-i}\right)\right)}{V_{y}}
$$

Where $E$ is the expected value, $V$ is the variance, $Y$ is the output (LCOE in our analysis), and $X_{-i}$ represents all input factors excluding the $i^{\text {th }}$. First order effects can also be calculated to measure the direct contribution of the input to the output variance, not including interactions with other inputs. If the first index is large, we cannot neglect the input in our analysis. Equation (2) shows the basic form for the first-order index, $S_{F i}$, using notation from (Saltelli et al., 2004).

$$
S_{F i}=\frac{v\left(E\left(Y \mid X_{i}\right)\right)}{V_{y}}
$$


Where $X_{i}$ is the $i^{\text {th }}$ input. It follows that $S_{F i} \leq S_{T i}$ for each input $i$, and the equality holds if the model is linear.

\section{Methods}

The following section describes the methods used for identifying soft cost inputs, defining distributions for each respective input, and calculating Sobol' indices to quantify the uncertainty of the output LCOE.

\subsection{CREST model design analysis}

The CREST Model is currently offered for online download in Microsoft Excel format (National Renewable Energy Laboratory, 2011) and comes in five versions for cost prediction of five energy sources: solar, wind, geothermal, anaerobic digestion, and fuel cells. To conduct the analysis presented in this paper, we rewrote the solar model in Python ${ }^{1}$ using NumPy and Pandas packages. We validated the Python model against the original model to ensure accuracy of our results.

\subsection{Assumptions for analysis}

To analyse the CREST model and quantify uncertainty of soft costs, we use the following assumptions for the PV solar project modelled here:

- The generator nameplate capacity (size of the solar project modelled) is 2 Megawatts (MW), the size of a typical "commercial-scale" PV project. Note that all power values in this paper refer to Direct Current (DC) values.

- The location of the project is California, U.S., which is used to generate the net capacity factor for power calculations.

- Federal Investment Tax Credit is set at 30\% and state rebates or tax credits are not considered.

- Interest rate on the term debt is $7 \%$ and interest rate on equity is $12 \%$, both consistent with industry benchmarks (Hubbell et al., 2009).

\subsection{Soft cost distributions}

To choose the soft cost inputs for analysis, we considered the current soft cost priorities in the US DoE. Based on these priorities and previous research studies conducted by NREL, we chose three major soft cost inputs for the analysis:

- Development Cost \& Fees are described in the model as “...All costs relating to project management, studies, engineering, permitting, contingencies, success fees, and other soft costs not accounted for elsewhere..."

- Land Lease Fees are described in the model as "...[The] fixed payments to the site host (and possibly other affected parties) for the use of the land on which the project is located."

- Interconnection Fees are described in the model as "...All project costs relating to connecting to the grid, such as the construction of transmission lines, permitting costs with the utility, and start-up costs. This category will also include the cost of a new substation, if necessary."

The following sections describe the distributions we used for each soft cost input.

\subsubsection{Development cost \& fees}

The Development Cost and Fee is under the Capital Cost section of the CREST model with the units of USD. This input is used as a general "catch-all' term for the soft costs associated with the project, not including the installation labour.

In the NREL 2018 Solar Cost Benchmark report for the first quarter (Jan.-Mar.) of the year, the authors reported the overall soft cost fees ranged from $26 \phi / \mathrm{W}$ to $85 \phi / \mathrm{W}$ for commercial/utility-scaled projects (Fu et al., 2018). Based on this information, we used these values as the lower and upper bounds for a uniform

\footnotetext{
${ }^{1}$ https://github.com/syalsm/CRESTSolarModelPython
} 
distribution. Scaling the values for a 2 MW solar PV project, Table 2 gives the bounds for the uniform distribution used to represent this input.

Table 2. Uniform distribution parameters for development cost and fees, values are based on (Fu et al., 2018)

\begin{tabular}{|c|c|}
\hline Lower Bound & Upper Bound \\
\hline$\$ 520,000$ & $\$ 1,718,000$ \\
\hline
\end{tabular}

\subsubsection{Land lease fees}

The Land Lease input is under the Operations and Maintenance Cost section of the CREST model and has units of USD/year. As the solar industry grows and the deployment of large-scaled solar PV farms increases, significant land use is a major concern for the industry (Ong et al., 2013). Developers rarely purchase land to build solar farms, due to lack of land plot availability and the amount of upfront capital required; developers typically lease land from landowners, often farmers, for the project duration (25-30 years after installation). Annual land lease costs and land use for solar PV projects vary based on the negotiated lease rate per acre, the amount of acreage a project requires, and the contract terms agreed upon. This process, referred to as "Landowner Acquisition," has received attention in the industry and literature, including studies on utilizing agricultural land for PV projects (North Carolina Clean Energy Technology Center, 2017), contract considerations for farmers from major trade organizations (Solar Energy Industries Association, 2016), and landowner guides produced by university agricultural extensions (Carroll, 2019; Romich, 2017).

An annual land lease cost requires three inputs: the project capacity $(M W)$, the annual lease rate (USD/acres), and the number of acres for the project (acres/MW). The first input is based on our assumption of a $2 \mathrm{MW}$ project for this analysis. The second input is typically a negotiated rate and is proprietary information; for this analysis, we assumed an average annual lease rate in California's central valley of $\$ 1000 /$ acre (Strategic Solar Group, 2019). The number of acres of land required for a particular sized project can vary; a team of researchers at NREL collected data from various-sized projects across the U.S. for solar PV projects to calculate land areas (Ong et al., 2013). The team collected official project data, project fact sheets/news releases, official project drawings, and other data provided by the developer or project owner, as well as used satellite imagery to fill in gaps of the data. Using the dataset built from California projects in the NREL analysis, we plotted a histogram of the acres/ $M W$ values, shown in Figure 1. We then fit a normal distribution, resulting in the following parameters: $N \sim(7.89,2.17)$.

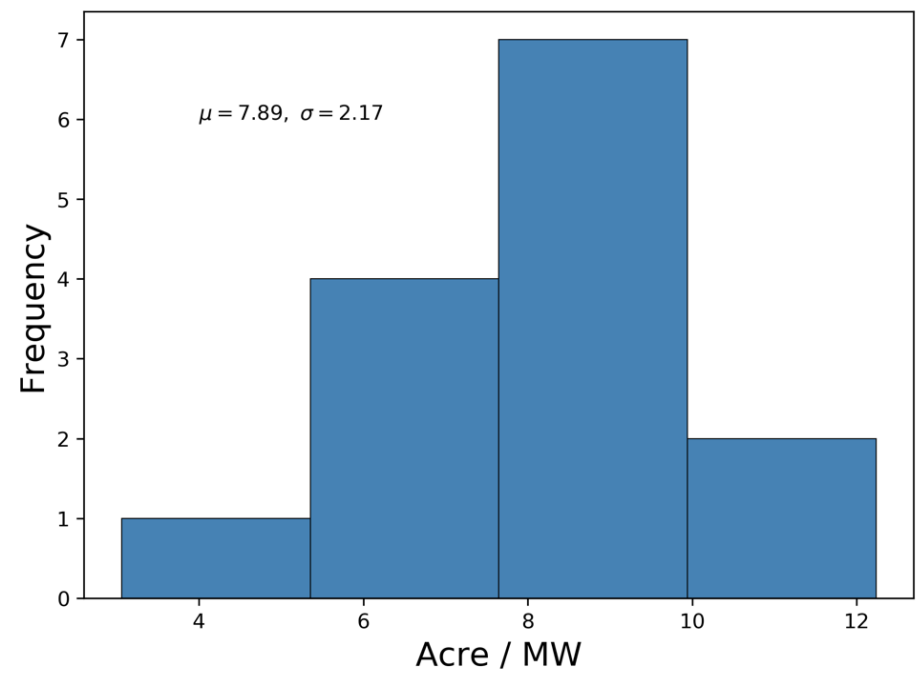

Figure 1. Distribution of acre / MW values for solar PV projects in California, values are based on (Ong et al., 2013) 
Using values from the normal distribution, we can calculate the annual Land Lease rate input to the model, as shown in Equation (3), where $L$ is the acres per MW determined by the distribution parameters.

$$
\text { Annual Land Lease Cost }=2 M W * L \frac{\text { acre }}{M W} * \frac{\$ 1000}{\text { acre }}
$$

\subsubsection{Interconnection fees}

The Interconnection input is under the Capital Cost section of the CREST model and has the units of $U S D$. With the increase in solar projects connecting to the grid, traditional investor-owned utilities have redefined their interconnection processes; in the transition, these processes are often poorly documented, fraught with delays, and depend on the individuals doing the inspections and labour; just the interconnection studies alone have been reported to vary from $\$ 2,500$ to $\$ 30,000$ for commercialscale solar projects (Friedman et al., 2013).

NREL conducted a review of the practices, processes, and costs of interconnection for 92 solar PV systems in Western U.S. grid (Bird et al., 2018). Through interviews and data collection, the researchers looked at the different processes and a range of potential barriers, including lack of application standardization, inspection delays, and excessive costs associated with the application process. The solar developer must take on all the costs required to connect to the grid, which may include application fees, application review, any costs associated with project start-up for the utility, and any potential upgrades to the grid.

For the projects within the capacity range of 0.1-5 MW, Bird et al. (2018) reported a cumulative interconnection fee range of $\$ 60,000 / \mathrm{MW}$ to $\$ 200,000 / \mathrm{MW}$. Scaling these bounds for a $2 \mathrm{MW}$ project, we used the following lower and upper bound to define a uniform distribution for the Interconnection input:

Table 3. Uniform distribution parameters for Interconnection input, values are based on (Bird et al., 2018)

\begin{tabular}{|c|c|}
\hline Lower Bound & Upper Bound \\
\hline$\$ 120,000$ & $\$ 400,000$ \\
\hline
\end{tabular}

\subsection{Sobol' index calculation}

To quantify the uncertainty of each soft cost input in the analysis, we calculated total-order index indices, as described in Section 2.3. Naïve computation of Sobol' indices require evaluation of integrals, thus can be computationally costly depending on the input distributions and model structure. Sobol' (1993) introduced a method for approximation using Monte Carlo sampling; for more information on implementation, see (Owen, 2013, pg. 23).

After investigating our cost model with the current inputs, we find that our model is nearly linear with the form:

$$
y=18.17+\left(2.7 \times 10^{-6}\right) x_{1}+\left(4.1 \times 10^{-5}\right) x_{2}+\left(4.2 \times 10^{-6}\right) x_{3} \quad \mathrm{R}^{2}=0.99
$$

Where $y$ is the output LCOE, $x_{1}$ is the Development Cost and Fees, $x_{2}$ is the Land Lease fees, and $x_{3}$ is the Interconnection fees. Using this linear form and the input distributions described above, the totalorder index can be calculated directly. Note that since the model is linear, the first-order indices will equal the total-order indices, thus only total-order indices are reported in the results. We use Effective Quadratures, an open-source Python library for uncertainty quantification, to calculate the indices using the linear model described in Equation (4) (Seshadri and Parks, 2017).

\section{Results}

The following figure shows the results of the Sobol' total-order index calculations.

The results show that the total-order index for Development Cost and Fee heavily outweighs the other indices calculated. The total-order index for the Land Lease input was significantly smaller than the other indices; a small total-order index indicates the Land Lease input is unimportant in the given analysis. This means we can be confident the Land Lease input contributes very little to the overall 
LCOE variability through individual effects or interaction effects, compared to the other inputs in our analysis.

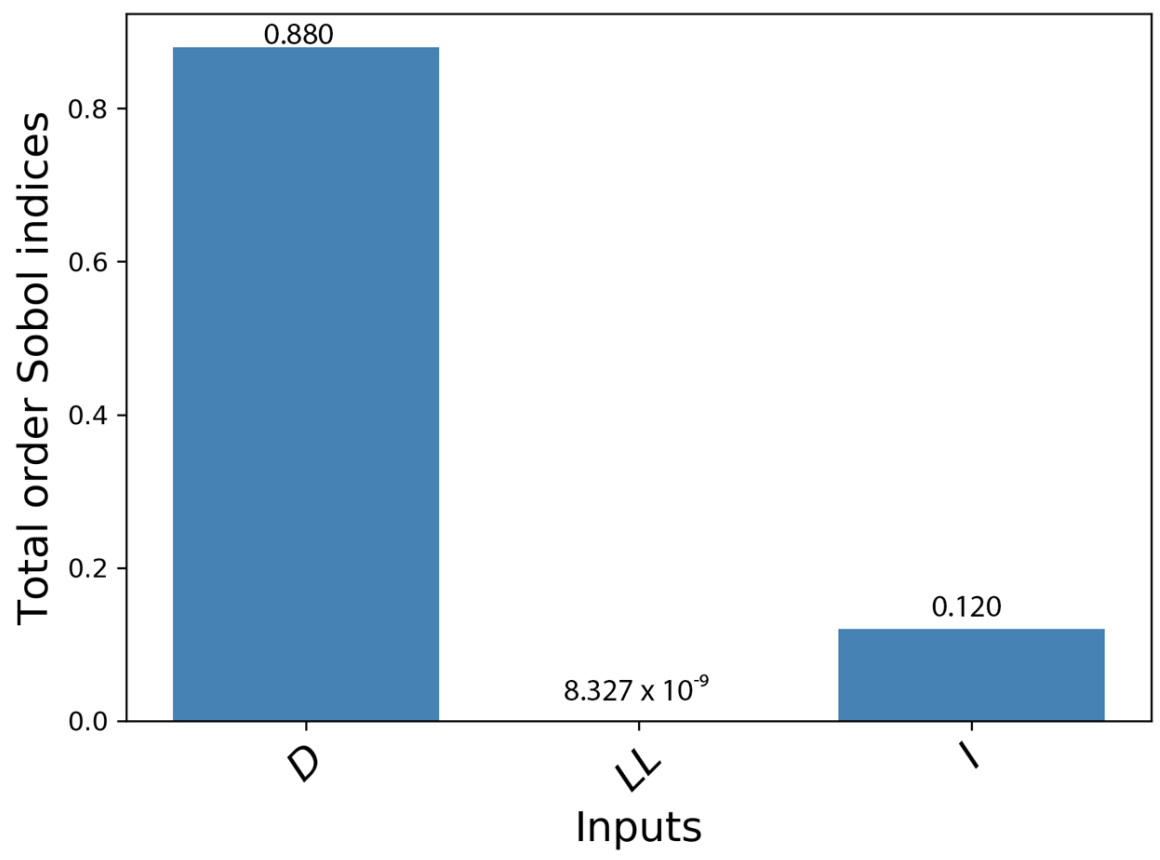

Figure 2. Total-order indices for Development cost and fees, land lease, and interconnection (left to right)

\section{Discussion}

The results show many interesting insights. First, the Development Cost and Fee was the most important soft cost input we analysed based on the index results; this index is both the largest value in magnitude and also the most difficult to quantify due to lack of industry data. The model is designed such that this particular cost input is a "catch-all" input that combines many uncertain variables that may not have publicly available data. The analysis suggests the Development Cost and Fees are the most important soft cost for determining LCOE, relative to the other soft costs in the analysis. We know from industry anecdotes that often these costs can significantly affect the output costs and design; however, the CREST model in its current form aggregates these costs and effectively simplifies the nuances of how this input could truly influence the system design. In future analyses, we suggest the Development Cost and Fee input should be deconstructed into its subcomponents and studied at a more granular level to understand which subcomponents contribute to the overall cost. The lack of data for these costs may be an immediate limitation to future analyses and should be further investigated. To address these challenges, future studies can include partnerships with developers and utilities, as well as interviews and surveys conducted with industry professionals, to better inform model design and cost data.

Second, the results of this analysis show that Land Lease costs are relatively unimportant to the variability of the LCOE, compared to the other soft cost inputs. Land lease costs and land use for solar projects have received industry and research attention, particularly in the agricultural industry, due to the high land requirements of large-scale solar projects. The analysis suggests that if the goal of the industry is to decrease LCOE for solar projects, designing programs and conducting research toward reducing land lease costs may not be the best use of efforts. Developers may want to design their development process to prioritize aspects such as reducing permitting costs and interconnection fees instead of optimizing landowner fee negotiations. One important caveat not included in this analysis is the landowner acquisition process for solar development has the potential to completely derail a project if a landowner declines to lease his or her land to the developer. The effects of these landowner-developer interactions are not taken into account in the analysis presented in this paper. 
Finally, the analysis provides insight into how the solar industry builds models to represent sociotechnical systems and how uncertainty is communicated (or not) when making crucial project decisions. The CREST model and others described in Table 1 are designed to incorporate soft costs in a mathematically simplistic manner, whereas industry data suggests soft costs are complicated and do not influence output costs and engineering design outcomes in a linear way. Quantifying uncertainty through variance-based indices introduces a new way to evaluate sociotechnical model design and provides interesting insights into how the development process can be redesigned. This analysis, and further studies in uncertainty quantification of soft cost inputs, can lead to more accurate cost predictions, better engineering designs, and more efficient project planning, ultimately leading to higher solar installation rates.

The analysis presented in this paper has many limitations that are worth noting. First, the NREL CREST model was last updated in 2013; the numbers used in the model may not accurately reflect the cost of solar projects by the time this paper is published. This shortcoming may limit how realistic the results are and may have biased the outputs. NREL currently offers a more detailed solar cost model called Systems Advisor Model (SAM), as described in Table 1. SAM has been validated with real industry data and may offer interesting insights as a next step to studying the uncertainty of solar soft cost inputs.

Second, the data used to build distributions for the three soft cost inputs was difficult to obtain, due to the proprietary nature of the industry. We based the distributions on data from studies in the literature, which may not reflect the true industry distribution. Data for the aggregated input, Development Cost and Fees, proved difficult to obtain and specific data relating to Interconnection costs are generally not publicly released. The distribution for Land Lease costs was slightly more reliable, due to the dataset available from NREL, however the calculations were still simplistic. In general, a limitation of this project was the lack of availability of data in the industry and literature.

Finally, limitations exist when calculating Sobol' indices. Inputs are required to be independent to calculate the indices, which we assumed in our analysis. In reality, this assumption may not hold true.

\section{Conclusion}

In this paper, we studied a publicly available solar cost model, the NREL CREST model, and quantified the uncertainty of soft cost inputs. We rewrote the CREST model from Microsoft Excel to Python for the analysis and chose three soft cost inputs to analyse - Development Cost and Fees, Land Lease, and Interconnection. Using publicly available industry data, we defined distributions for each soft cost and calculated the total-order Sobol' indices for the resulting linear model. The indices were used to determine the relative importance of each input with respect to output LCOE variability and provide insight into the CREST model design of soft cost inputs. We found that the Development Cost and Fees were most important in the analysis; however, this input was simplified mathematically in the model. We recommend studying the uncertainty of this input at more granular level to determine the uncertainty and influence of its subcomponents. We also found that Land Lease costs were relatively unimportant to the variability of the output LCOE and development efforts working toward reducing this cost may not be as important in practice as reducing Development Cost and Fees and Interconnection Fees to achieve lower project costs. Overall, quantifying the uncertainty of soft costs provides a new way for the solar industry to consider the uncertainty of human-driven costs and how sociotechnical models are designed to account for these complex uncertainties. Additionally, this analysis suggests improvements for the development process and suggests focus areas to reduce soft costs; ultimately, with the goal to accelerate solar installations.

\section{Acknowledgements}

We would like to thank Zach del Rosario for his help on the content this paper, especially his notes on Global Sensitivity and Sobol' Indices. This work was funded by a National Science Foundation Graduate Fellowship. 


\section{References}

Bird, L. et al. (2018), Review of Interconnection Practices and Costs in the Western States, [online] National Renewable Energy Laboratory. Available at: https://www.nrel.gov/docs/fy18osti/71232.pdf (accessed 1.8.2019). https://doi.org/10.2172/1435904

Blair, N. et al. (2017). System Advisor Model (SAM) General Description (Version 2017.9.5). [online] National Renewable Energy Laboratory. Available at: https://www.nrel.gov/docs/fy18osti/70414.pdf (accessed 30.10.2019). https://doi.org/10.2172/1440404)

BP (2019), BP Energy Outlook, 2019 Edition, [online] BP. Available at: https://www.bp.com/energyoutlook. (accessed 1.8.2019)

Carroll, M. (2019), "Considerations for Transferring Agricultural Land to Solar Panel Energy Production", [online] North Carolina Cooperative Extension. Available at: https://craven.ces.ncsu.edu/considerations-fortransferring-agricultural-land-to-solar-panel-energy-production/ (accessed 1.8.2019).

Department of Energy (2019), Soft Costs, [online] Available at: https://www.energy.gov/eere/solar/soft-costs (accessed 1.4.2019).

Friedman, B. et al. (2013), Benchmarking Non-Hardware Balance-of-System (Soft) Costs for U.S. Photovoltaic Systems, Using a Bottom-up Approach and Installer Survey - Second Edition. [online] National Renewable Energy Laboratory. Available at: https://www.nrel.gov/docs/fy14osti/60412.pdf (accessed 30.10.2019). https://doi.org/10.2172/1107461

Fu, R., Feldman, D. and Margolis, R. (2018), U.S. Solar Photovoltaic System Cost Benchmark: Q1 2018, [online] National Renewable Energy Laboratory. Available at: https://www.nrel.gov/docs/fy19osti/ 72399.pdf (accessed 30.10.2019). https://doi.org/10.2172/1483475

Hubbell, R. et al. (2009), Renewable Energy Finance Tracking Initiative (REFTI) Solar Trend Analysis, [online] National Renewable Energy Laboratory. Available at: https://www.nrel.gov/docs/fy12osti/53531.pdf (accessed 30.10.2019). https://dx.doi.org/10.2172/1052498

National Renewable Energy Laboratory (2011), Renewable Energy Project Finance: CREST Cost of Energy Models, [online] National Renewable Energy Laboratory. Available at: https://www.nrel.gov/analysis/cres t.html (accessed 1.9.2019).

North Carolina Clean Energy Technology Center (2017), Balancing Agricultural Productivity with GroundBased Solar Photovoltaic (PV) Development, [online] North Carolina State University. Available at: http://ncsolarcen-prod.s3.amazonaws.com/wp-content/uploads/2017/10/Balancing-Ag-and-Solar-finalversion-update.pdf (accessed 15.9.2019).

Ong, S. et al. (2013), Land-Use Requirements for Solar Power Plants in the United States, [online] National Renewable Energy Laboratory. Available at: https://www.nrel.gov/docs/fy13osti/56290.pdf (accessed 30.10.2019). https://doi.org/10.2172/1086349

Owen, A.B. (2013), "Variance components and generalized Sobol' indices", SIAM/ASA Journal of Uncertainty Quantification, Vol. 1, pp. 19-41. https://doi.org/10.1137/120876782

Pianosi, F. et al. (2016), "Sensitivity analysis of environmental models: A systematic review with practical workflow", Environmental Modelling and Software, Vol. 79, pp. 214-232. https://doi.org/10.1016/j.e nvsoft.2016.02.008

PVSyst (2019), PVSyst Photovoltaic Software, [online] PVSyst. Available at: https://www.pvsyst.com/ (accessed 1.11.2019).

Romich, E. (2017), Considerations for Utility Scale Solar Farm Land Lease Agreements, [online] The Ohio State University. Available at: https://u.osu.edu/extensioncd/2017/02/23/considerations-for-utility-scalesolar-farm-land-lease-agreements/comment-page-1/ (accessed 15.10.2019).

Saltelli, A. et al. (2004), Sensitivity Analysis in Practice: A Guide to Assessing Scientific Models, John Wiley \& Sons Ltd, West Sussex. https://doi.org/10.1002/0470870958

Seshadri, P. and Parks, G. (2017), "Effective-Quadratures (EQ): Polynomials for Computational Engineering Studies", Journal of Open Source Software, Vol. 2 No. 11, p. 166. https://doi.org/10.21105/joss.00166

Sobol', I.M. (1993), "Sensitivity Estimates for Nonlinear Mathematical Models", Mathematical Modelling and Computational Experiments, Vol. 1 No. 4, pp. 407-14.

Solar Energy Industries Association (2016), Guide to Land Leases for Solar, [online] Solar Energy Industries Association. Available at: https://www.seia.org/research-resources/seia-guide-land-leases-solar (accessed 1.10.2019).

Strategic Solar Group (2019), What Is the Average Solar Farm Lease Rate, [online] Strategic Solar Group. Available at: https://strategicsolargroup.com/what-is-the-average-solar-farm-lease-rate/ (accessed 1.9.2019).

US Department of Energy (2016a), Solar Energy Evolution and Diffusion Studies 2 - State Energy Strategies (SEEDSS2-SES), [online] US Solar Energy Technologies Office. Available at: https://www.energy. 
gov/eere/solar/funding-opportunity-announcement-solar-energy-evolution-and-diffusion-studies-2-state (accessed 1.10.2019).

US Department of Energy (2016b), Soft Cost Fact Sheet, [online] Sunshot US Department of Energy. Available at: https://www.energy.gov/sites/prod/files/2016/05/f32/SC\%20Fact\%20Sheet-508.pdf (accessed 1.9.2019).

Valentin Software (2019), PV*SOL Premium, [online] Valentin Software. Available at: https://www.valentinsoftware.com/en/products/photovoltaics/57/pvsol-premium (accessed 1.11.2019). 